\title{
Effects of bee density and sublethal imidacloprid exposure on cluster temperatures of caged honey bees
}

\author{
William G. MeiKLe ${ }^{1}$, John J. AdAmCZyK ${ }^{2}$, Milagra Weiss ${ }^{1}$, Ales Gregorc ${ }^{2}$ \\ ${ }^{1}$ Carl Hayden Bee Research Center, USDA-ARS, Tucson, AZ, USA \\ ${ }^{2}$ Southern Horticultural Laboratory, USDA-ARS, Poplarville, MS, USA
}

Received 22 February 2018 - Revised 10 May 2018 - Accepted 18 July 2018

\begin{abstract}
Survivorship, syrup consumption, and cluster temperatures of honey bees were kept in hoarding cages with different numbers of bees. Cages with either 50,100, 150, or 200 bees each were monitored over 4-6 weeks in incubators with $12 \mathrm{~h} / 12 \mathrm{~h} 30^{\circ} \mathrm{C} / 15^{\circ} \mathrm{C}$ temperature cycles to induce clustering. Survivorship and syrup consumption rates per bee were not different among the bee density groups, but cluster temperatures were. Cluster temperatures ranged from $0.45^{\circ} \mathrm{C}$ above incubator temperature in the 50 bee cages to $4.05^{\circ} \mathrm{C}$ in the 200 bee cages over the $1 \mathrm{st}$ 7 days, with each additional bee adding on average $0.02^{\circ} \mathrm{C}$ to cluster temperature. In another set of experiments, cages were established with about 200 bees each, and imidacloprid added to the syrup at $0,5,20$, and $100 \mathrm{ppb}$. Imidacloprid in the syrup did not affect bee survivorship but it did reduce syrup consumption per bee, with bees fed $100 \mathrm{ppb}$ imidacloprid syrup consuming on average $631 \mathrm{mg}$ per bee over 28 days while average consumption among the other groups ranged from 853 to $914 \mathrm{mg}$. Cluster temperature was affected by imidacloprid treatment: bees fed $5 \mathrm{ppb}$ imidacloprid syrup had higher cluster temperatures over the $1 \mathrm{st} 10$ days, $4.17^{\circ} \mathrm{C}$ above incubator temperature, than either bees fed $100 \mathrm{ppb}$ syrup or control ( 2.35 and $3.19^{\circ} \mathrm{C}$, respectively).
\end{abstract}

\section{sublethal dose / neonicotinoid / continuous monitoring / Apis / hoarding cages}

\section{INTRODUCTION}

Honeybee colonies have been described as "superorganisms" (Southwick and Mugaas 1971; Moritz and Southwick 1992; Schmolz et al. 1994) because honey bees behave collectively in ways that isolated or solitary bees do not, such as protecting the colony against diseases and pests (Evans and Spivak 2010) and regulating internal conditions in the hive (Human et al. 2006; Stabentheiner et al. 2010). How effectively honey bee colonies perform these collective behaviors has been considered with respect to colony genetics,

Electronic supplementary material The online version of this article (https://doi.org/10.1007/s13592-018-0585-z) contains supplementary material, which is available to authorized users.

Corresponding author: W. Meikle, william.meikle@ars.usda.gov

Manuscript editor: James Nieh phenology, and health. The capacity of a colony to regulate colony temperature, for example, has been found to be a function of the honey bee subspecies (W-Worswick 1987), the within-colony genetic diversity (Jones et al. 2004), and phenological status (Stalidzans and Berzonis 2013).

The effects of pesticide exposure on bee health have been the subject of much recent research, and sublethal exposure of neonicotinoid pesticides such as imidacloprid has been implicated in bee health issues (Blacquière et al. 2012; Dively et al. 2015; Krupke et al. 2012). Neonicotinoid pesticides have been associated with reduced foraging success (Henry et al. 2012), increased forager mortality (Henry et al. 2015), olfactory associative behavior (Yang et al. 2012), altered thoracic temperature (Tosi et al. 2016), increased Nosema spore densities (Pettis et al. 2012), reduced colony growth and hive temperature control (Meikle et al. 2016a), and other health and behavior changes at the individual and colony level (Gill et al. 2012). The $\mathrm{LC}_{50}$ of 
imidacloprid, $1760 \mathrm{ng} / \mathrm{L}$, is far above what is considered "field realistic" (Cresswell 2011); a survey of pollen samples in the USA showed a low incidence of imidacloprid ( $<3 \%$ of samples) with an average concentration of $39 \mathrm{ppb}$ (Mullin et al. 2010). Exposure to imidacloprid at very low concentrations (5 ppb in sugar syrup) in controlled field experiments has been associated with increased flight activity (Meikle et al. 2016a), suggesting that effects on bee health at very low concentrations may be mixed.

Thoracic temperatures of honey bees and bumblebees have been shown to be affected by low concentrations of neonicotinoid pesticides (Tosi et al. 2016; Potts et al. 2018). Bee cluster temperature is necessarily a group-level parameter; therefore, how cluster temperature is affected by pesticide exposure may indicate ways that exposure affects other behaviors. Internal hive temperature in the field is necessarily affected by factors such as presence of brood and to some extent ambient temperature (Gates 1914; Meikle et al. 2016b; Stabentheiner et al. 2010). Monitoring cluster temperature in the laboratory would allow for the control of many of those confounding factors. To measure cluster temperature in hoarding cages in the laboratory, cluster behavior must be induced, such as by using a warm/ cool cycle in a variable-temperature incubator. Allowing the bees to warm up for part of the cycle permits them to move about and feed. Temperature was monitored via sensors placed in locations likely to be inside the cluster. Because the number of bees in the cluster likely affects the temperature regime inside the cluster, the effects of different numbers of bee in the cages were measured. Minimum size for cluster formation has been observed to be about 75 bees (Lecomte 1950); however, clustering behavior in that study was not temperature-induced, as was done here. Finally, the cluster temperatures of caged bees exposed to various concentrations of imidacloprid in sugar syrup were monitored in the variable-temperature environments.

\section{MATERIALS AND METHODS}

\subsection{Bee density studies}

In general, published recommendations for cage studies of honey bees (Williams et al. 2013) were employed in these studies. In August 2017, at the Carl Hayden Bee Research Center (CHBRC) in Tucson, AZ (31 ${ }^{\circ} 46^{\prime} 38.08^{\prime \prime} \mathrm{N}$, $\left.110^{\circ} 51^{\prime} 47.39^{\prime \prime} \mathrm{W}\right)$, several frames of mature brood were removed from each of four 6-monthold colonies with Cordovan Italian queens (C.F. Koehnen \& Sons, Inc). The hives had been visually inspected for disease symptoms and monitored every 2-3 months for Varroa infestation and had been treated against Varroa using amitraz the previous November. The frames were placed in an incubator (Percival model I36VL) at $30^{\circ} \mathrm{C}$ and $50 \%$ r.h. Adult bees emerging over the following $48 \mathrm{~h}$ were distributed among 28 hoarding cages until cages had either $50,100,150$, or 200 bees ( 7 replicate cages per group). The hoarding cages had internal dimensions of $115 \mathrm{~mm} \times$ $100 \mathrm{~mm} \times 65 \mathrm{~mm}$ : narrow sides and top made of Plexiglas ${ }^{\circledR}$ and the broad sides and bottom made of 3-m-aperture galvanized steel mesh (see Online Resource 1 Figs. S1-S3). A plastic $50-\mathrm{mL}$ bottle for water and a plastic $30-\mathrm{mL}$ bottle for syrup, each with a small hole in the lid, were inverted and placed on top of each cage. A $4 \times$ $4 \mathrm{~cm}^{2}$ of wax foundation was attached to a piece of screen that was hung, using two thin gauge wires, from the top of the cage so the square itself rested about 2-3 cm from the top of the cage, under the syrup and water bottles. Two Thermochron iButtons (Maxim Integrated, San Jose, CA, USA) were attached to the center of the square, one on either side, and programmed to record temperature every $20 \mathrm{~min}$. All cages were placed on one of three shelves in the incubator; placement was random with respect to treatment group. Temperature sensors were also placed in Petri dishes on each shelf in the incubator in order to control for temperature gradients within the incubator. In one experiment, those sensors were also placed in hoarding cages as described above but with no bees, but the difference between those sensors and sensors simply exposed in Petri dishes, on average $0.004^{\circ} \mathrm{C}$, was judged negligible. A mixture of $10 \mathrm{~g}$ each of pollen (Natural Foods Inc., Toledo, $\mathrm{OH}$ ), sucrose, and inverted sucrose was placed on the day bees were placed in the cages, inside a rubber gasket accessed via a hole in the side of the cage. Dead bees were removed and counted 2-3 times per week. 
Sucrose solution was prepared with $500 \mathrm{~g}$ sucrose and $500 \mathrm{~mL}$ distilled water in a mixing flask heated to no more than $60^{\circ} \mathrm{C}$; syrup consumption was measured weekly by weighing bottles of syrup at least twice per week; vials were emptied and refilled with fresh syrup weekly.

Newly emerged bees were kept for 1 week at $35^{\circ} \mathrm{C}$. Thereafter, the incubator temperature was set to vary: $12 \mathrm{~h}$ at $30^{\circ} \mathrm{C}$ and $12 \mathrm{~h}$ at $15^{\circ} \mathrm{C}$. Cages were checked daily to observe the bee clustering behavior with respect to the temperature sensors. Clusters were described as either symmetric over the sensors (i.e., more or less evenly distributed on either side of the wax square and covering the sensors), mostly clustered under the sugar bottle or water bottle and covering the sensors, clustered elsewhere in the cage and not covering the sensors, or not clustered. After 5 weeks, the remaining bees were placed in a freezer, all remaining bees counted in each cage, and the temperature sensors extracted and downloaded.

The experiment was repeated at SHRU in Poplarville with a total of 24 cages (6 cages per treatment group). Honey bee colonies were established In April 2015 from packages with Italian queens from the same breeding line (Gunter Honey, Inc., Lumberton, MS) in new 10-frame Langstroth deep boxes (Dadant \& Sons, Inc.) at the Mississippi State University Coastal Experiment Station in McNeill, MS (30 39' 46" N, 89 $\left.38^{\prime} 01^{\prime \prime} \mathrm{W}\right)$. Brood frames were selected from three hives. After filling the cages, all cages were placed at $30^{\circ} \mathrm{C}$ in a stable-temperature incubator (Percival model E367). After 1 week, all cages were moved to the variable-temperature incubator.

Adult bee survivorship in cage studies was analyzed using Proc LifeReg (SAS Inc. 2002). An appropriate distribution was first chosen to model survivorship; survivorship curves were generated for each replicate cage based on that model, and treatments compared using ANOVA ( $\alpha=0.05$ ) (Proc Glimmix, SAS Inc. 2002) with respect to three parameters: (1) the 30th percentile; (2) the 50th percentile; and (3) a shape variable calculated by subtracting the 40th from the 30 th percentile. Cluster temperatures were analyzed by subtracting the incubator temperature, as measured on the shelf of a given cage, from the cage temperature, calculated as the average of the two sensors in the cage, and then averaging those temperature differences over the first $6 \mathrm{~h}$ of the cold cycle. Repeated measures MANOVA $(\alpha=0.05)$, using the ante(1) variance/covariance model, with post hoc comparisons of treatment using the Bonferroni error rate correction.

Consumption per bee was calculated as the observed consumption for a given cage divided by the number of "bee-days" for that time period, in which a bee-day represents one bee alive for 1 day in that cage and calculated as the total syrup consumption for a given period divided by the average between the bee density at the beginning and end of that time period (while bees were counted as they were placed in the cages, for accuracy the actual cage value was determined at the end of the experiment) (see Meikle et al. 2016a). Consumption data in cages with fewer than six bees were removed from the analyses because error associated with the feeding bottles (e.g., losses due to occasional drops from the bottle) was high compared to the amount of syrup those bees consumed. Weekly averages were calculated and analyzed using repeated measures MANOVA $(\alpha=0.05)$, using the ante(1) variance/covariance model, with post hoc comparisons of treatment using the Bonferroni error rate correction.

\subsection{Imidacloprid exposure studies}

Experiments evaluating the effect of low concentrations of imidacloprid in sugar syrup were conducted in a similar fashion. All cages were populated with approximately 200 newly emerged bees. The bees were fed pollen supplement, water, and syrup in the same fashion as above. Prior to the experiment, sugar syrup was prepared using water-soluble analytical-grade imidacloprid (Pestanal, CAS \# 138261-41-3) as described in Meikle et al. (2016a). Briefly, uncontaminated sucrose solution for the control treatment was made with $500 \mathrm{~g}$ sucrose and $500 \mathrm{~mL}$ distilled water as described above. Solutions for imidacloprid treatments were made using $500 \mathrm{~g}$ of sugar is dissolved in $400 \mathrm{~mL}$ of distilled water to allow for the addition of a $100 \mathrm{~mL}$ imidacloprid solution, or "spike," to achieve $1 \mathrm{~kg}$ treatment 

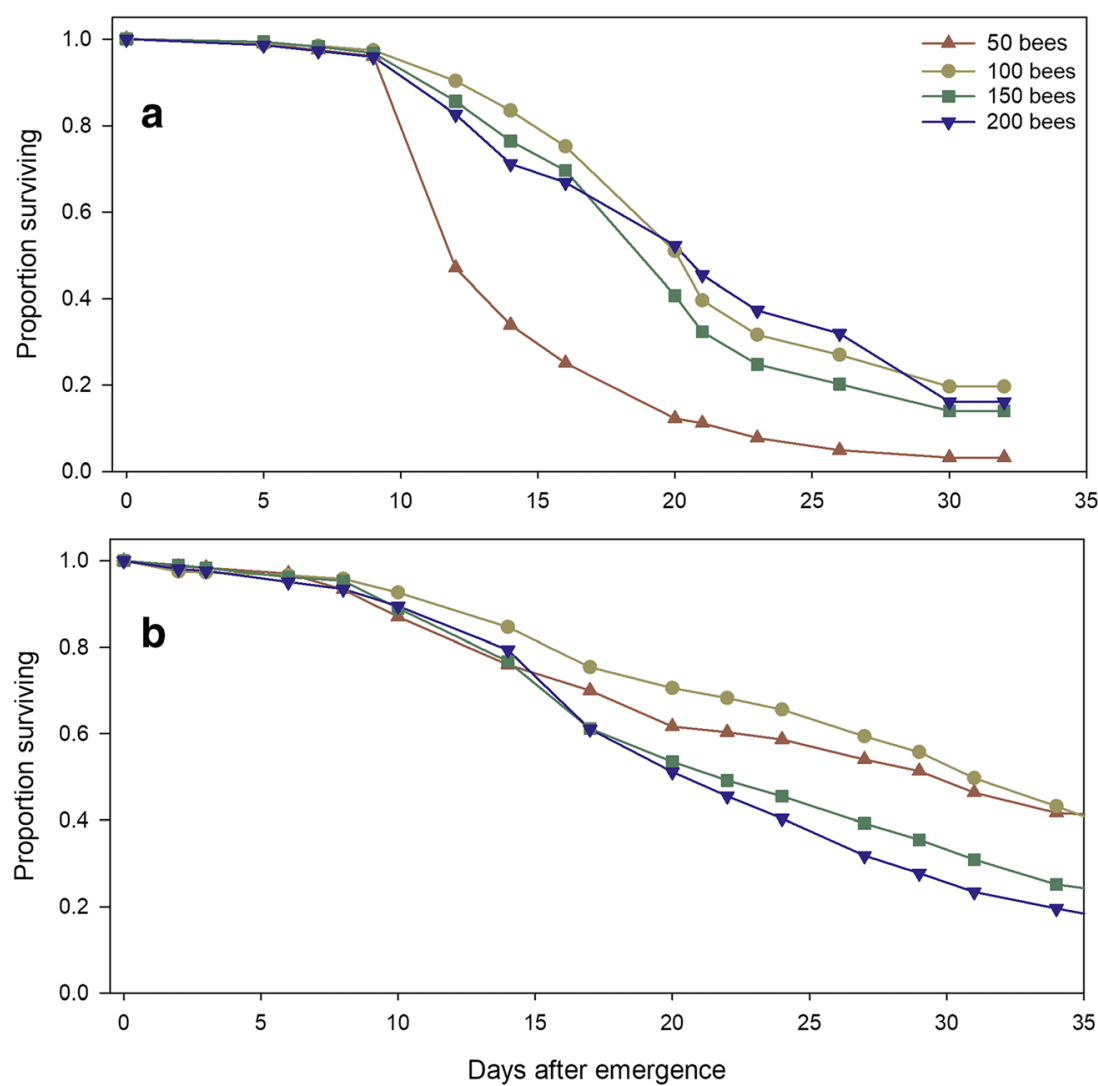

Figure 1. Proportion surviving over time for two experiments involving varying numbers of bees per cage. a Experiment conducted at CHBRC. b Experiment conducted at SHRU. Treatment groups were not significantly different (See Online Resource 2 Table S1).

solution of 1:1 $w: w$ solution. Nine hundred grams of the concentrated syrup was transferred to a Nalgene bottle, then the $100 \mathrm{ml}$ imidacloprid solution added to each individual bottle. To prepare the imidacloprid solutions, a 10 ppm imidacloprid stock solution was made by dissolving $1.0 \mathrm{mg}$ of imidacloprid, in $100 \mathrm{~mL}$ of distilled water without heat. For the $5 \mathrm{ppb}$ solution, $0.5 \mathrm{~mL}$ of the imidacloprid stock solution was mixed into $99.5 \mathrm{~mL}$ of distilled water to achieve $100 \mathrm{~mL}$ of spike solution, which was then added to $900 \mathrm{~g}$ of the concentrated syrup to achieve $1 \mathrm{~kg}$ of $5 \mathrm{ppb}$ imidacloprid syrup. Similarly, for the $20 \mathrm{ppb}$ solution, $2.0 \mathrm{~mL}$ of stock solution was mixed into $98.0 \mathrm{~mL}$ of distilled water to make the spike, and for the $100 \mathrm{ppb}$ solution, $10.0 \mathrm{~mL}$ of stock solution was mixed into $90.0 \mathrm{~mL}$ of distilled water to make the spike. Those spikes were added to $900 \mathrm{~g}$ of the concentrated syrup to achieve $1 \mathrm{~kg}$ of the respective imidacloprid concentration in 1:1 syrup. Samples of treatment solutions prepared in this manner have been shown to provide the target concentrations with an error of $<10 \%$ (see Meikle et al. 2016a). Dead bees were removed using dedicated equipment and latex gloves to avoid cross contamination. The experiment was conducted twice at CHBRC with 24 and 30 cages, and once at SHRU 20 cages. The experiment at SHRU was staggered because of the large number of bees involved: two cages per treatment were filled at the start and 5 days later the remaining cages were filled. Statistical analyses were conducted as for the bee density studies (please see above). Data from all the bee density and imidacloprid studies are provided (see Online Resource 3). 


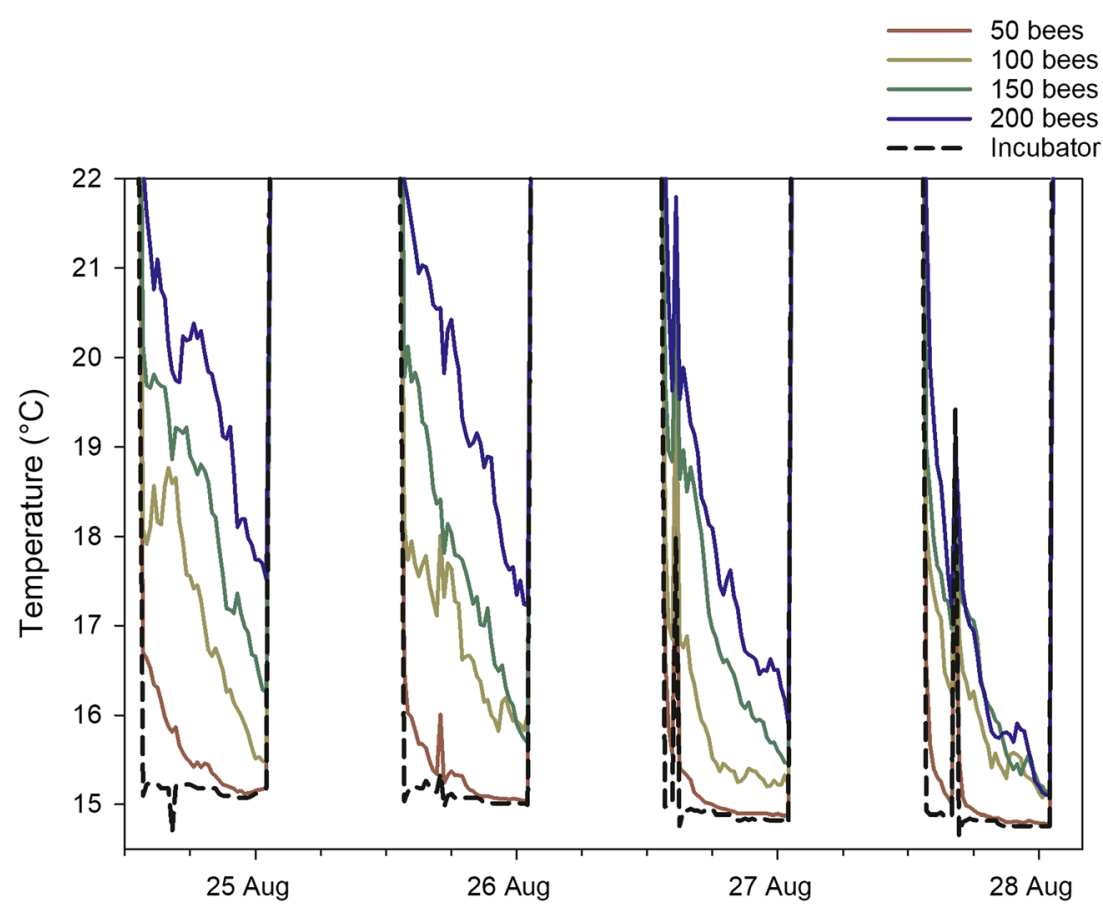

Figure 2. Cluster and incubator temperatures over several days in an experiment involving varying numbers of bees per cage. Shown are data from day 2 to day 5 after the start of the variable-temperature cycle. Temperature spikes were due to workers opening the incubator door to assess the clustering behavior.

\section{RESULTS}

\subsection{Bee density studies}

The 30th and 50th percentiles, and the difference between the 30th and 40th percentiles of the honey bee survivorship curves, were not significantly affected by the density of bees in each cage ( $P>0.14$ for all comparisons) (Figure 1) (See Online Resource 2 Table S1). The two experiments were themselves significantly different with respect to those parameters $(P<0.002$ for all comparisons). One issue was a malfunction with the incubator at SHRU that was detected after the experiment: rather than a $12 \mathrm{~h} / 12 \mathrm{~h} 30^{\circ} \mathrm{C} / 15^{\circ} \mathrm{C}$ cycle, the incubator rose to $35^{\circ} \mathrm{C}$ for $3 \mathrm{~h}$, dropped for several minutes to $22^{\circ} \mathrm{C}$, then rose to $30^{\circ} \mathrm{C}$ for $10 \mathrm{~h}$, with only about $7 \mathrm{~h}$ at $15^{\circ} \mathrm{C}$. Bees in the SHRU experiment survived significantly longer than those at CHBRC, reaching 50\% mortality across all treatments after 28.2 days compared to 20.4 days at CHBRC, possibly because of the reduced time the bees spent at $15^{\circ} \mathrm{C}$. This may have played a role in the noticeably different survivorship of the 50 bee groups between the CHBRC and SHRU studies. Considering the two experiments together, there was a significant interaction between treatment and experiment with respect to the 30th and 50th percentiles ( $P<0.01$ for both comparisons) but not the shape parameter $(P=0.23)$. Bee density did not affect syrup consumption per bee $(P=0.27)$, nor were consumption rates different between experiments $(P=0.33)$ (See Online Resource 2 Table S2).

Cluster temperatures, as well as treatment differences, tended to decline during the $15^{\circ} \mathrm{C}$ phase (this was observed in all experiments) and maximum resolution was judged to be during the first $6 \mathrm{~h}$ (Figure 2) so temperature differences were calculated using data from the first $6 \mathrm{~h}$ at $15^{\circ} \mathrm{C}$. Bee density had a significant and strong effect on cluster temperature $(P<0.0001)$ (See Online Resource 2 Table S3). All groups were significantly different from each other (Table I), and the cluster temperatures in the SHRU experiment were significantly higher, $2.32^{\circ} \mathrm{C}$, than those in 
Table I. Differences of least squares means for treatment groups $(50,100,150$, and 200 bees per cage) with respect to daily difference between cluster temperature and incubator temperature $\left(15^{\circ} \mathrm{C}\right)$ over the 1 st 14 days in a variabletemperature incubator (Table III) for two experiments conducted at different locations (Tucson and Poplarville)

\begin{tabular}{lllllrr}
\hline Group 1 & Group 2 & \multicolumn{1}{l}{ Value } & SE & DF & $t$ value & \multicolumn{1}{c}{ Adj $P$} \\
\hline 100 bees & 50 bees & 1.0229 & 0.2779 & 40.16 & 3.68 & 0.0041 \\
100 bees & 150 bees & -0.8004 & 0.2759 & 39.66 & -2.90 & 0.0361 \\
100 bees & 200 bees & -1.6616 & 0.2759 & 39.66 & -6.02 & $<0.0001$ \\
150 bees & 50 bees & 1.8232 & 0.2779 & 40.16 & 6.56 & $<0.0001$ \\
150 bees & 200 bees & -0.8612 & 0.2759 & 39.66 & -3.12 & 0.0200 \\
200 bees & 50 bees & 2.6845 & 0.2779 & 40.16 & 9.66 & $<0.0001$ \\
\hline
\end{tabular}

Adjustment for multiple comparisons: Bonferroni

the $\mathrm{CHBRC}$ experiment, $1.32^{\circ} \mathrm{C}$, again probably due at least in part to the differences in incubator temperature regime. Daily differences between cluster temperature and incubator temperature tended to decline during the course of the experiment, and after 3-4 weeks differences among treatments and between cluster and incubator temperatures tended to become very small (Figure 3). Cluster temperatures ranged from $0.45^{\circ} \mathrm{C}$ above incubator temperature in the 50 bee cages to $4.05^{\circ} \mathrm{C}$ in the 200 bee cages over the 1 st 7 days. Average cluster temperature above incubator temperature for the first 7 days was regressed on bee density for each experiment. The slope of the CHBRC regression line $\left(F_{1,22}=76.16\right.$; $P<0.0001$; adj. $\left.r^{2}=0.77\right)$ was 0.023 ( $t$ value $=$ $8.73 ; P<0.0001)$ and was similar to the slope of the SHRU regression line $\left(F_{1,26}=36.17\right.$; $P<0.0001$; adj. $\left.r^{2}=0.57\right)$ of 0.019 ( $t$ value $=$ $6.01 ; P<0.0001)$ (Figure 4). These slopes indicate that, on average, each additional bee added about $0.02^{\circ} \mathrm{C}$ to the cluster temperature above the 50 -bee average. The largely homoscedastic distribution of the data suggests that relationship between bees and temperature was essentially additive.

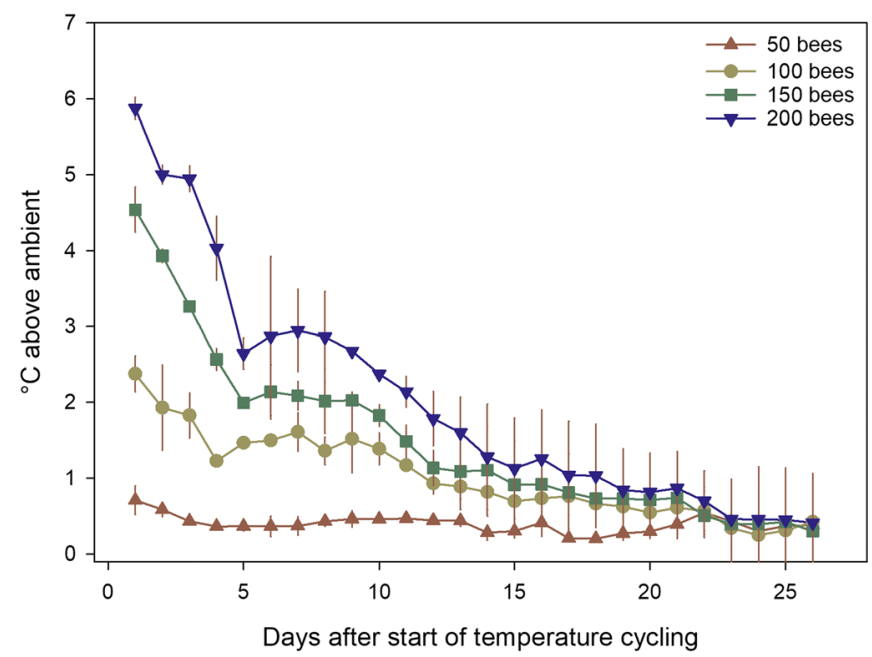

Figure 3. Temperature difference over time between bee cluster and incubator temperature for four treatment groups: bee cages stocked with $50,100,150$, or 200 bees. Shown are average and s.e. for the average values of two experiments. All curves were significantly different from each other (see Table I). 


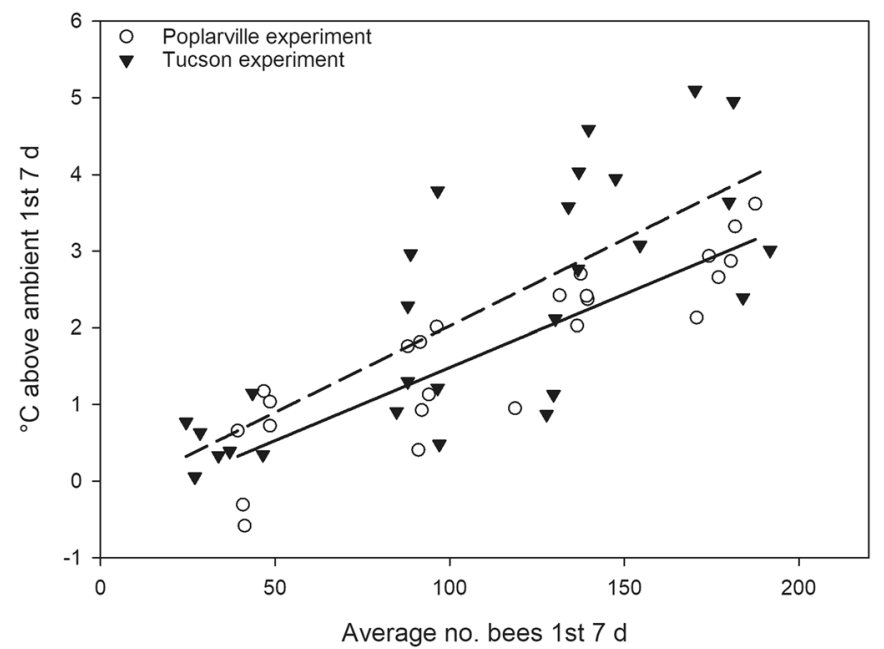

Figure 4. Average temperatures over the first 7 days regressed on the average number of bees per cage over the first 7 days for two experiments. Dashed line: regression of CHBRC (Tucson) experiment data, slope $=0.023$; solid line: regression of SHRU (Poplarville) experiment data, slope $=0.019$.

\subsection{Imidacloprid exposure studies}

Honey bee survivorship was not significantly affected by the exposure of bees to imidacloprid at the concentrations used in this study $(P>0.12$ for all comparisons) (Figure 5) (See Online Resource 2 Table S4). Although differences among the three experiments were significant $(P<0.005$ for all comparisons), the interaction between experiment and treatment was not $(P>0.30$ for all comparisons) indicating that relationships among treatment groups were similar within experiment. When compared directly, the experiments differed among themselves with respect to the distribution parameters with no experiment being clearly different from the other two (See Online Resource 2 Table S5).

Syrup consumption rates differed both among treatments and across experiments $(P<0.0001$ for all comparisons) (See Online Resource 2 Table S6). Bees fed syrup containing $100 \mathrm{ppb}$ imidacloprid clearly consumed less, on average $631 \mathrm{mg}$ per bee over 28 days, than did bees fed syrup with $20 \mathrm{ppb}(854 \mathrm{mg}), 5 \mathrm{ppb}(911 \mathrm{mg})$, or control $(914 \mathrm{mg})$, None of the other treatment groups was significantly different from each other (Table II). Among the three experiments, bees in the June 2017 experiment at SHRU consumed significantly more syrup than bees in any other experiment $(P<0.0001$ for all comparisons $)$ (See Online Resource 2 Table S7), possibly due to the shorter cold phase, allowing bees more time to consume syrup. The differences among experiments indicate that bees had variable exposure to the imidacloprid, but the treatment $\times$ experiment interaction was not significant $(P=0.33)$.

Two adjustments were made to the data sets regarding bee cluster temperatures. In the first case, cluster behavior was reviewed and data for one cage in the $5 \mathrm{ppb}$ treatment group (in the July 2016 experiment at CHBRC) were removed because their cluster was poorly placed (the bees clustered at the bottom of the wax square, without overlapping either sensor). In the second case, data from three cages in the SHRU experiment, one each in the 5,20, and $100 \mathrm{ppb}$ treatment groups, were removed because at the end of the experiment it was determined that those cages did not have at least 170 bees per cage; the previous analysis (see above) demonstrated the importance of bee density.

Bee cluster temperatures were significantly different both with respect to treatment and experiment (both $P<0.0001$ ) and the interaction of treatment with experiment $(P=0.016)$ (See 


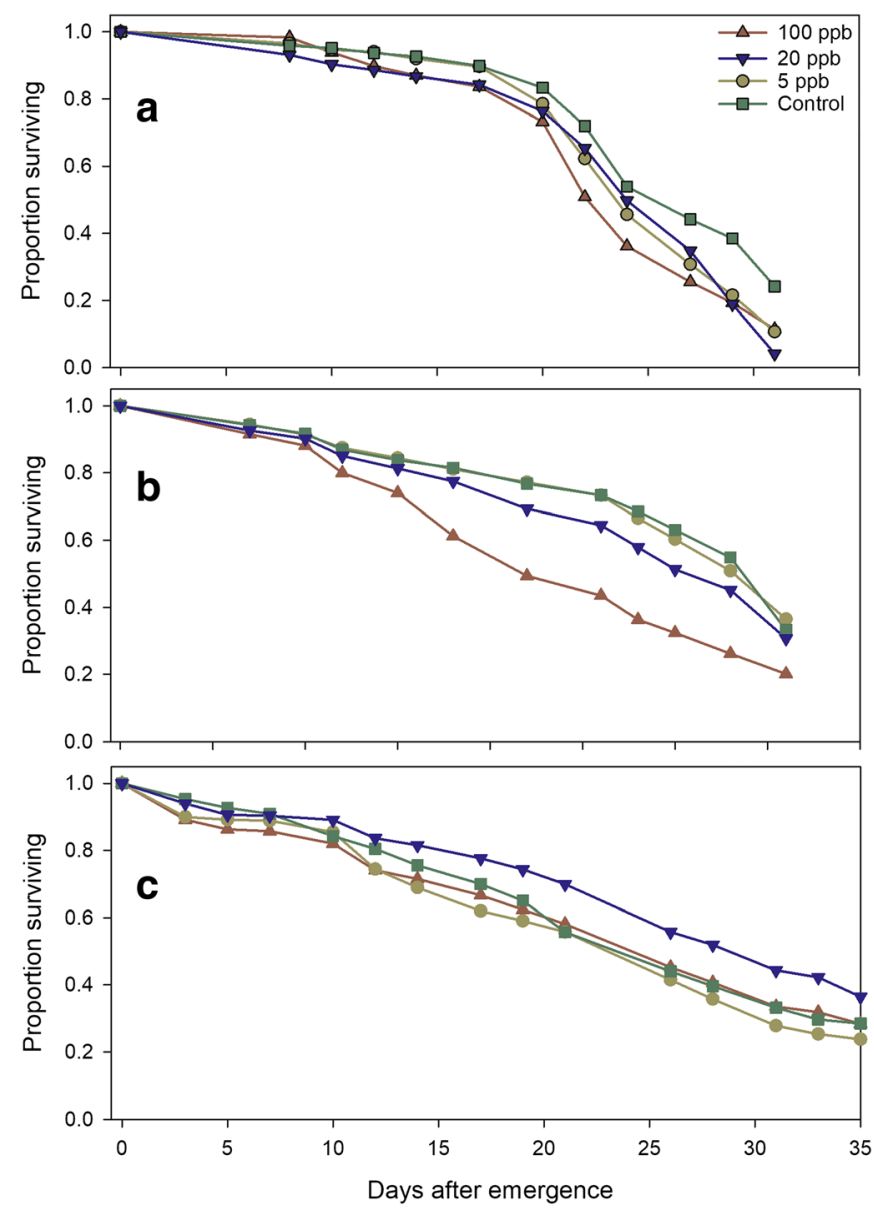

Figure 5. Survivorship curves for cages of 200 bees used in three experiments on pesticide exposure. Bees were fed one of four treatments - sugar syrup mixed with imidacloprid at (1) $100 \mathrm{ppb}$, (2) $20 \mathrm{ppb}$, (3) $5 \mathrm{ppb}$, and (4) $0 \mathrm{ppb}$ (control). a Experiment conducted at CHBRC, AZ, in July 2016. b Experiment conducted at CHBRC, AZ, in April 2017. c Experiment conducted at SHRU, MS, in June 2017. Treatment groups were not significantly different (See Online Resource 2 Table S4).

Online Resource 2 Tables S8 and S9). Post hoc contrasts showed that cluster temperatures in the April 2017 experiment (CHBRC) were on average the lowest overall $\left(1.99^{\circ} \mathrm{C}\right.$ above incubator) and the temperatures for the July 2016 experiment $(\mathrm{CHBRC})$ were highest $\left(4.30^{\circ} \mathrm{C}\right)$. Across all experiments, bees fed $5 \mathrm{ppb}$ imidacloprid had a significantly higher temperature $\left(4.18^{\circ} \mathrm{C}\right)$ than the control $\left(3.21^{\circ} \mathrm{C}\right)$. Cluster temperatures for bees fed $100 \mathrm{ppb}$ imidacloprid $\left(2.34^{\circ} \mathrm{C}\right.$ above incubator) were significantly lower than those for bees fed either $20\left(3.34^{\circ} \mathrm{C}\right)$ or $5 \mathrm{ppb}$ imidacloprid (Table III).

\section{DISCUSSION}

Temperature control by honey bees is crucial for brood rearing (Stabentheiner et al. 2010) and some degree of temperature control is evident among groups of bees even in the absence of brood (Meikle et al. 2017). Maintaining the cluster temperature is a metabolically expensive activity of the colony for much of the year (Gates 1914; Milner 1921). Internal hive temperature over time has been linked to changes in colony size and phenology (Meikle et al. 2016b, 2017) and thus can be a useful variable to monitor hive status. In a 
Table II. Differences of least squares means for treatment groups (caged bees fed syrup with either 100, 20, 5 or $0 \mathrm{ppb}$ imidacloprid) with respect to the weekly average of the daily consumption per bee in a variable-temperature incubator measured at two locations (Tucson and Poplarville) (see Online Resource 2 Table S6)

\begin{tabular}{lllllll}
\hline Group 1 & Group 2 & Value & SE & DF & $t$ value & Adj $P$ \\
\hline $100 \mathrm{ppb}$ & $5 \mathrm{ppb}$ & -10.1886 & 2.1916 & 42.4 & -4.65 & 0.0002 \\
$100 \mathrm{ppb}$ & Control & -10.2837 & 2.1916 & 42.4 & -4.69 & 0.0002 \\
$100 \mathrm{ppb}$ & $20 \mathrm{ppb}$ & -8.0657 & 2.2155 & 42.1 & -3.64 & 0.0044 \\
$5 \mathrm{ppb}$ & Control & -0.09509 & 2.1627 & 42.4 & -0.04 & 1.0000 \\
$5 \mathrm{ppb}$ & $20 \mathrm{ppb}$ & 2.1229 & 2.1869 & 42.1 & 0.97 & 1.0000 \\
Control & $20 \mathrm{ppb}$ & 2.2180 & 2.1869 & 42.1 & 1.01 & 1.0000 \\
\hline
\end{tabular}

Adjustment for multiple comparisons: Bonferroni

colony in the field, cluster temperature is maintained largely through the combined action of exothermic bees, which can raise their thoracic temperatures in excess of $45^{\circ} \mathrm{C}$, combined with insulation properties due to the structure of the cluster itself (Stabentheiner et al. 2010).

Cluster temperatures were affected by bee density, with each additional bee adding about $0.02^{\circ} \mathrm{C}$ on average to the cluster temperature over the first 7 days of the experiment, or days 8-14 post emergence. In these studies, newly emerged bees were kept at $30^{\circ} \mathrm{C}$ for 7 days prior to being subjected to the temperature cycling, to allow the bees to develop sufficiently before exposing them to a stressful environment. Bees $<2$ days old have been found to be ectothermic and thus unable to contribute heat to a cluster, but after 2 days post emergence, an adult bee is facultatively endothermic until the end of its life (Stabentheiner et al.
2010). Neither syrup consumption rates per bee nor bee survivorship differed among the treatment groups; however, survivorship was different between the two experiments, probably due at least in part to the incubator malfunction. Honey bee colony thermoregulation is also known to have an important genetic component (Jones et al. 2004) so genetic differences between the two groups may have also played a role.

Within 7-10 days after the start of the experiment (bee ages 14-17 days), temperature maintenance in the cage clusters dropped off considerably, suggesting that caged bees were either unable or disinclined to maintain cluster temperature at previous levels. This reduction in temperature maintenance over time indicated a difference between the cage clusters in these studies and clusters of bees in healthy colonies. Cage clusters differed from bee colony clusters in three main respects: (1) cage

Table III. Differences of least squares means for treatment groups (200 bees per cage fed syrup with either 100, 20, 5 , or $0 \mathrm{ppb}$ imidacloprid) with respect to the daily difference between cluster temperature and incubator temperature $\left(15^{\circ} \mathrm{C}\right)$ in a variable-temperature incubator (see Online Resource 2 Table S8) over the 1 st 10 days of the experiment

\begin{tabular}{lllllrr}
\hline Group 1 & Group 2 & Value & SE & DF & $t$ value & \multicolumn{1}{c}{ Adj $P$} \\
\hline $100 \mathrm{ppb}$ & $5 \mathrm{ppb}$ & -1.8384 & 0.3496 & 63.8 & -5.26 & $<0.0001$ \\
$100 \mathrm{ppb}$ & Control & -0.8652 & 0.3351 & 63.2 & -2.58 & 0.0729 \\
$100 \mathrm{ppb}$ & $20 \mathrm{ppb}$ & -1.0032 & 0.3451 & 63.2 & -2.91 & 0.0302 \\
$5 \mathrm{ppb}$ & Control & 0.9732 & 0.3397 & 63.8 & 2.86 & 0.0339 \\
$5 \mathrm{ppb}$ & $20 \mathrm{ppb}$ & 0.8353 & 0.3496 & 63.8 & 2.39 & 0.1192 \\
Control & $20 \mathrm{ppb}$ & -0.1379 & 0.3351 & 63.2 & -0.41 & 1.0000 \\
\hline
\end{tabular}

Adjustment for multiple comparisons: Bonferroni 
clusters were considerably smaller, with 50-200 bees, than colony clusters, which would typically have 8000 bees (about a $\mathrm{kg}$ ) or more; (2) cage clusters consisted of bees all the same age, whereas colony clusters have a much broader age distribution; and (3) colony clusters typically have brood and/or a queen to stimulate temperature or synchronize behavior, whereas the cage clusters did not. It is likely that the linear relationship between bee number and cluster temperature observed here with up to 200 bees is just one part of a more complex relationship as bee number increases.

Temperature magnitude was positively correlated with bee cluster size in the laboratory. A similar relationship was observed in honey bee colonies in the field (Meikle et al. 2016b). However, there are important differences between laboratory and field studies with respect to the meaning of the temperature changes. Sensors were placed in bee cages to maximize the probability that the sensors were at or near the center of the cluster most of the time (in one case the bee cluster never overlapped the sensor so those data were removed). Whether bee clusters in cages have any structure was not clear from these studies but cluster cohesion clearly varied, although it was difficult to quantify. The interpretation of temperature data from within a bee hive is more complex. A sensor at a fixed location within a bee hive, as is typically done in field studies, would be affected both by the movement of the cluster (Szabo 1989) and by the cluster size, as the cluster grows and shrinks over time, changing cluster boundaries. A sensor near the exterior of the cluster in a hoarding cage, and thus partly influenced by the incubator temperature, would record a change, even if the temperature at the core of the cluster had not changed (Meikle and Holst 2015). Bee clusters in hives are also known to have structure, with higher densities of endothermic bees on the interior and one or more layers of non-endothermic bees acting as insulation around the exterior (Stabentheiner et al. 2010). Temperature magnitude and variability within a hive may therefore be a function of cluster location, size, and cohesion, since that may affect the efficiency of the insulating layer. Further work is needed to determine how the results in these cage studies might correspond to effects in the field.
Syrup consumption rates and cluster temperature were both reduced among cages fed $100 \mathrm{ppb}$ imidacloprid. Bees fed 100 ppb imidacloprid consumed significantly less syrup, on average $631 \mathrm{mg}$ per bee over 28 days, than bees in the other groups, which ranged from 853 to $914 \mathrm{mg}$. The bees in the $100 \mathrm{ppb}$ group also had significantly smaller difference between cluster and incubator temperatures $\left(2.35^{\circ} \mathrm{C}\right)$ than either the $5 \mathrm{ppb}$ or $20 \mathrm{ppb}$ groups (4.17 and $3.32^{\circ} \mathrm{C}$, respectively), but not the control group $\left(3.19^{\circ} \mathrm{C}\right)$. Honey bees have been found to prefer sucrose syrup containing low concentrations of imidacloprid to blank syrup but bees fed imidacloprid-laced syrup consumed less syrup overall than those fed only blank syrup (Kessler et al. 2015). Lower syrup consumption rates by bees fed syrup with $100 \mathrm{ppb}$ imidacloprid, as well as lower hive temperature, have been reported in field trials (Meikle et al. 2016a).

Cluster temperatures were significantly higher for bees fed $5 \mathrm{ppb}$ imidacloprid syrup than control bees and those fed 100 ppb imidacloprid syrup over the 1 st 10 days. Cluster temperatures declined over time, due at least in part to declining numbers of bees per cage, but the temperature difference between the $5 \mathrm{ppb}$ and control treatments declined at a much faster rate than could be explained by bee loss. While the difference in bee mortality between the $5 \mathrm{ppb}$ and control treatments was on average $<2 \%$ after 10 days, the difference in cluster temperature had declined by about $16 \%$, from 1.32 to $1.11^{\circ} \mathrm{C}$ (see Figures 5, 6, and 7). Further research is needed on bees of different ages to see if the decline in pesticide effect was a function of bee age or due to other factors such as pesticide habituation. Thoracic temperatures of bumble bees have been shown to be stimulated by low concentrations (< $1.5 \mathrm{ppb}$ ) of imidacloprid, but not thiamethoxam, another neonicotinoid (Potts et al. 2018).

Increased flight activity has been observed among honey bee colonies fed 5 ppb imidacloprid compared to control colonies (Meikle et al. 2016a); while internal hive temperature was monitored as well in that study, no significant differences were observed among treatment groups. Since bees apparently provided heat on an additive basis according the results of the studies on bee density, with more bees resulting in higher temperatures, the 


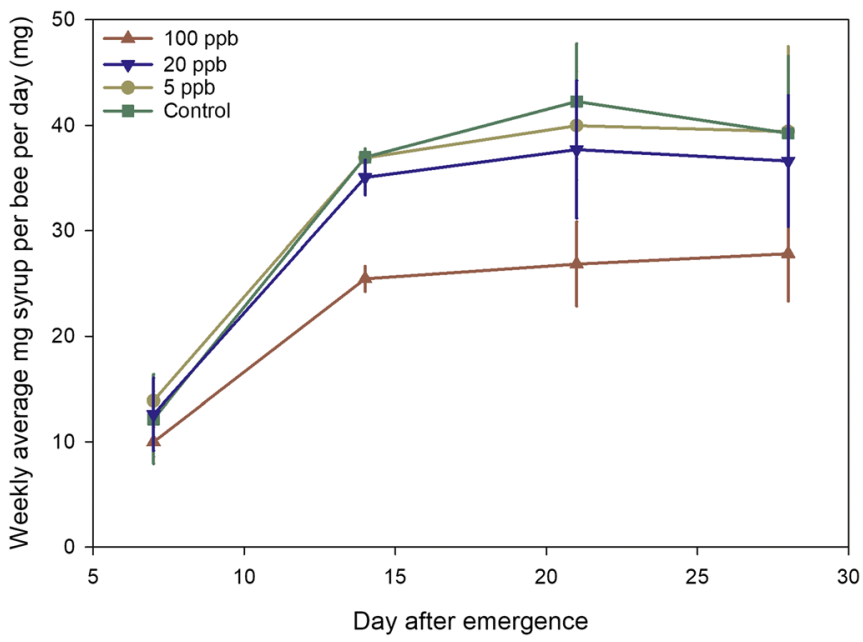

Figure 6. Weekly average and s.e. of the daily syrup consumption per bee per day across the average values of three experiments. Bees were fed one of four treatments - sugar syrup mixed with imidacloprid at (1) $100 \mathrm{ppb}$, (2) $20 \mathrm{ppb}$, (3) $5 \mathrm{ppb}$, and (4) $0 \mathrm{ppb}$ (control). Bees in the $100 \mathrm{ppb}$ treatment group consumed significantly less syrup than bees other treatment groups $(P \leq 0.0044)$ and no other comparisons were significant (see Table II).

higher cluster temperatures among the bee groups fed 5 ppb imidacloprid implies that each bee provided more heat to the cluster than did control bees. Imidacloprid affects insect nicotinic acetylcholine receptors (Tomizawa and Casida 2005) and honey bees have a tolerance for concentrations of nicotine, 0.1 to $5 \mathrm{ppm}$, found naturally in some nectars (Singaravelan et al. 2006). The survival of bees from "weak" colonies (those exhibiting a lack of vigor for undetermined reasons) has been shown to improve when placed in cages and given a $300 \mu \mathrm{M}$, or about $48.6 \mathrm{ppm}$, nicotine solution (Köhler et al. 2012) or about $10^{4}$ higher than a $5 \mathrm{ppb}$ imidacloprid solution. Whether the bees were "healthier" with the $5 \mathrm{ppb}$ imidacloprid was not determined here. Other factors may have played a role. Bees in the June 2017 cage experiment at SHRU consumed significantly more syrup

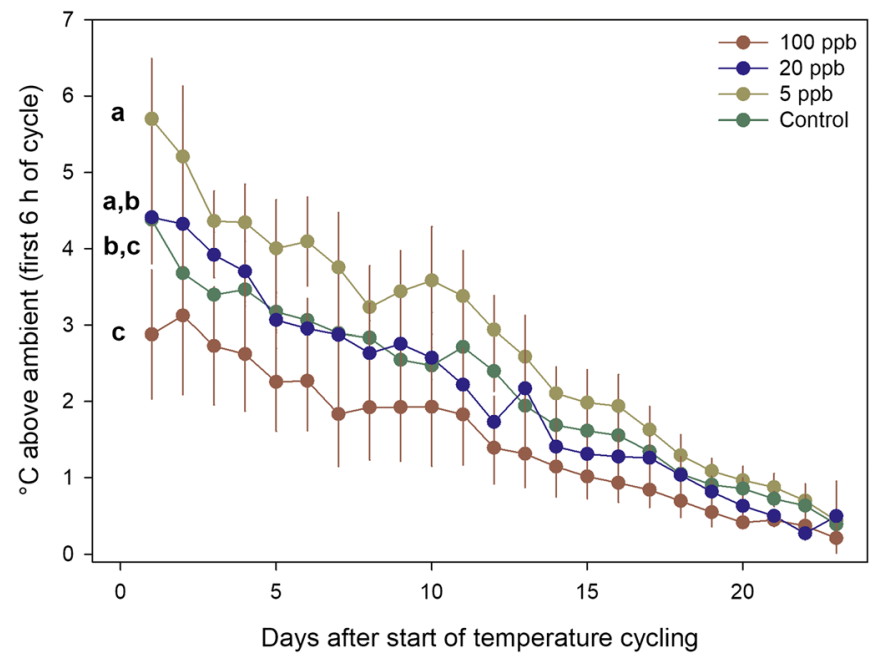

Figure 7. Average and s.e. of temperature difference between bee cluster and incubator temperature over time across the average values of three experiments. Curves with no common letters (left side of the graph) are significantly different at $P<0.04$ (see Table III). 
than bees in other experiments for reasons that are unclear, so those bees consumed, on average, higher doses of imidacloprid than bees in the same treatment group in other experiments.

In this study, we demonstrated that hoarding cages with even comparatively small groups of bees can generate measurable cluster temperatures over 1-2 weeks when placed in a variabletemperature environment. Using this novel experimental design, we were able to measure significant effects of imidacloprid-laced sugar syrup at field-realistic concentrations (5 ppb). These results are consistent with effects of imidacloprid on thoracic temperatures of bumble bees (Potts et al. 2018), and with field measurements of hive temperatures among honey bee colonies subjected to similar concentrations. These results suggest that such an experimental design involving groups of bees in a controlled setting may be a useful tool to help bridge the gap between laboratory studies of individual bees and field studies of honey bees.

\section{ACKNOWLEDGEMENTS}

The authors would like to thank E. Beren and J. Ross for valuable technical assistance, and V. Corby-Harris, C. Werle, and two anonymous reviewers for improving the manuscript.

\section{AUTHORS' CONTRIBUTIONS}

WGM, JJA, and MW conceived this research and designed experiments; MW and GA performed experiments and analysis; WGM, JJA, MW, and AG wrote the paper and participated in all revisions. All authors read and approved the final manuscript.

\section{OPEN ACCESS}

This article is distributed under the terms of the Creative Commons Attribution 4.0 International License (http://creativecommons.org/licenses/by/4.0/), which permits unrestricted use, distribution, and reproduction in any medium, provided you give appropriate credit to the original author(s) and the source, provide a link to the Creative Commons license, and indicate if changes were made.

Effets de la densité des abeilles et de l'exposition sublétale à l'imidaclopride sur les températures des grappes d'abeilles en cage
Dose sublétale / néonicotinoïde / surveillance continue / Apis / hoarding cages

Effekte der Bienendichte und sublethaler Dosen von Imidacloprid auf die Temperatur der Bienentraube bei gekäfigten Honigbienen

Sublethale Dose / Neonikotinoid / kontinuierliche Beobachtung / Apis / Flugkäfig

\section{REFERENCES}

Blacquière, T., Smagghe G., van Gestel, C.A.M., Mommaerts, V. (2012) Neonicotinoids in bees: a review on concentrations, side-effects and risk assessment. Ecotoxicology 21, 973-992. https://doi. org/10.1007/s10646-012-0863-x.

Cresswell, J.E. (2011) A meta-analysis of experiments testing the effects of a neonicotinoid insecticide (imidacloprid) on honey bees. Ecotoxicology 20, 149-157. https://doi.org/10.1007/s10646-010-0566-0

Dively, G.P., Embrey, M.S., Kamel, A., Hawthorne, D.J., Pettis, J.S. (2015) Assessment of chronic sublethal effects of imidacloprid on honey bee colony health. PLoS ONE 10(3), e0118748. https://doi.org/10.1371 /journal.pone.0118748

Evans, J.D., Spivak, M. (2010) Socialized medicine: Individual and communal disease barriers in honey bees. J. Invertebr. Pathol. 103, S62-S72

Gates, B. (1914) The temperature of the bee-colony. Bull. US. Dept. Agric. 96, 1-19

Gill, R.J., Ramos-Rodriguez, O., Raine, N.E. (2012) Combined pesticide exposure severely affects individualand colony-level traits in bees. Nature 491, 105-109. https://doi.org/10.1038/nature11585

Henry, M., Béguin, M., Requier, F., Rollin, O., Odoux, J.F., Aupinel, P., et al. (2012) A common pesticide decreases foraging success and survival in honey bees. Science 336, 348-350. https://doi.org/10.1126 /science.1215039

Henry, M., Cerrutti, N., Aupinel, P., Decourtye, A., Gayrard, M., Odoux, J.-F., Pissard, A., Rüger, C., Bretagnolle, V. (2015) Reconciling laboratory and field assessments of neonicotinoid toxicity to honeybees. Proc. R. Soc. B. 282, 20152110

Human, H., Nicolson, S.W., Dietemann, V. (2006) Do honeybees, Apis mellifera scutellata, regulate humidity in their nest? Naturwissenschaften 93, 397-401

Jones, J.C., Meyerscough, M.R., Graham, S., Oldroyd, BP. (2004) Honey Bee nest thermoregulation: Diversity promotes stability. Science 305 (5682), 402-404. https://doi.org/10.1126/science. 1096340

Kessler, S.C., Tiedeken, E.J., Simcock, K.L., Derveau, S., Mitchell, J., Softley, S., Stout, J.C., Wright, G.A. (2015) Bees prefer foods containing neonicotinoid 
pesticides. Nature 521, 74-76. https://doi.org/10.1038 /nature14414

Köhler, A., Pirk, C.W.W., Nicolson, S.W. (2012) Honeybees and nectar nicotine: Deterrence and reduced survival versus potential health benefits. J. Ins. Physiol. 58(2), 286-292

Krupke, C.H., Hunt, G.J., Eitzer, B.D., Andino, G., Given, K. (2012) Multiple routes of pesticide exposure for honey bees living near agricultural fields. PLoS ONE 7(1), e29268. https://doi.org/10.1371/journal. pone. 0029268

Lecomte, J. (1950) Sur le determinisme de la formation de la grappe chez les abeilles. Z. Vgl. Physiol. 32(5), 499506. https://doi.org/10.1007/BF00339925

Meikle, W.G., Adamczyk, J.J., Weiss, M., Gregorc, A., Johnson, D.R., Stewart, S.D., et al. (2016a) Sublethal effects of imidacloprid on honey bee colony growth and activity at three sites in the U.S. PLoS ONE 11(12), e0168603. https://doi.org/10.1371/journal. pone. 0168603

Meikle, W.G., Holst, N. (2015) Application of continuous monitoring of honey bee colonies. Apidologie 46, 1022. https://doi.org/10.1007/s13592-014-0298-x

Meikle, W.G., Weiss, M., Maes, P.W., Fitz, W., Snyder, L.A., Sheehan, T., Mott, B.M., Anderson, K.E. (2017) Internal hive temperature as a means of monitoring honey bee colony health in a migratory beekeeping operation before and during winter. Apidologie 48, 666-680. https://doi.org/10.1007/s13592-017-0512-8.

Meikle, W.G., Weiss, M., Stilwell, A.R. (2016b) Monitoring colony phenology using within-day variability in continuous weight and temperature of honey bee hives. Apidologie 47, 1-14

Milner, E.F. (1921) Heat production of honeybees in winter, United States Department of Agriculture, Dept. Bull. No. 988

Moritz, R.F.A., Southwick, E.E. (1992) Bees as superorganisms: An evolutionary reality. Springer, Heidelberg

Mullin, C.A., Frazier, M., Frazier, J.L., Ashcraft, S., Simonds, R., VanEngelsdorp, D., Pettis, J.S. (2010) High levels of miticides and agrochemicals in North American apiaries: implications for honey bee health. PLoS ONE 5, e9754. https://doi.org/10.1371/journal. pone. 0009754

Pettis, J.S., vanEngelsdorp, D., Johnson, J., Dively, G. (2012) Pesticide exposure in honey bees results in increased levels of the gut pathogen Nosema. Naturwissenschaften 99, 153-158. https://doi. org/10.1007/s00114-011-0881-1

Potts, R., Clarke, R. M., Oldfield, S. E., Wood, L. K., Hempel de Ibarra, N., Cresswell, J. E. (2018) The effect of dietary neonicotinoid pesticides on non-flight thermogenesis in worker bumble bees (Bombus terrestris). J. Insect. Physiol. 104, 33-39. https://doi. org/10.1016/j.jinsphys.2017.11.006.
Schmolz, E., Lamprecht, I., Schricker, B. (1994) A method for continuous direct calorimetric measurements of energy metabolism in intact hornet (Vespa crabro) and honeybee (Apis mellifera ) colonies. Thermochem. Acta 251, 293-301

Singaravelan, N., Inbar, M., Ne'eman, G., Distl, M., Wink, M., Izhaki, I. (2006) The effects of nectar-nicotine oncolony fitness of caged honeybees. J. Chem. Ecol. 32(1), 49-59. https://doi.org/10.1007/s10886-0069350-2

Southwick, E.E., Mugaas, J.N. (1971) A hypothetical homeotherm: The honey bee hive. Comp. Biochem. Physiol. 40A, 935-944

Stabentheiner, A., Kovac, H., Brodschneider, R. (2010) Honeybee colony thermoregulation-regulatory mechanisms and contribution of individuals in dependence on age, location and thermal stress. PLoS ONE 5(1), e8967. https://doi.org/10.1371/journal. pone. 0008967

Stalidzans, E., Berzonis, A. (2013) Temperature changes above the upper hive body reveal the annual development periods of honey bee colonies. Comput. Electron. Agric. 90, 1-6

Szabo, T.I. (1989) Thermology of wintering honey-bee colonies in 4-colony packs. Am. Bee J. 189, 554-555

Tosi, S., Démares, F. J., Nicolson, S. W., Medrzycki, P., Pirk, C.W.W., Human, H. (2016) Effects of a neonicotinoid pesticide on thermoregulation of African honey bees (Apis mellifera scutellata). J. Insect Physiol. 93-94, 56-63. https://doi.org/10.1016/j. jinsphys.2016.08.010

Tomizawa, M., Casida, J.E. (2005) Neonicotinoid insecticide toxicology: Mechanisms of selective action. Annu. Rev. Pharmicol. Toxicol. 45, 247-268

Williams, G.R., Alaux, C., Costa, C., Csáka, T., Doublet, V., Eisenhardt, D., Fries, I., Kuhn, R., McMahon, D.P., Medrczyki, P., Murray, T.E., Natsopoulu, M.E., Neumann, P., Oliver, R., Paxton, R.J., Pernal, S.F., Shutler, D., Tanner, G., van der Steen, J.J.M., Brodschneider, R. (2013) Standard methods for maintaining adult Apis mellifera in cages under in vitro laboratory conditions. In Dietemann V, Ellis J D, Neumann P (Eds) The COLOSS BeeBook, Volume I: standard methods for Apis mellifera research. J. Apic. Res. 52(1). https://doi. org/10.3896/IBRA.1.52.1.04

W-Worswick, P.V. (1987) Comparative study of colony thermoregulation in the African honeybee, Apis mellifera adansonii Latreille and the Cape honeybee, Apis mellifera capensis Escholtz. Comp. Biochem. Physiol. 86A(1), 95-102

Yang, E.-C., Chang, H.-C., Wu, W.-Y., Chen, Y.-W. (2012) Impaired olfactory associative behavior of honeybee workers due to contamination of imidacloprid in the larval stage. PLoS ONE 7(11), e49472. https://doi. org/10.1371/journal.pone.0049472 